\title{
Using Mortierella alpina as a Novel Platform for Lipid Synthesis Inhibitor Screening
}

\author{
Md. Shofiul Azam ${ }^{1,2,3}$, Zhennan Gu ${ }^{1,2}$, Haiqin Chen ${ }^{1,2}$, Yong Q. Chen ${ }^{1,2}$ \\ ${ }^{1}$ State Key Laboratory of Food Science and Technology, School of Food Science and Technology, Jiangnan University, Wuxi, People's \\ Republic of China \\ ${ }^{2}$ Center of Excellence for Functional Food and Health, School of Food Science and Technology, Jiangnan University, Wuxi, People's \\ Republic of China \\ ${ }^{3}$ Department of Food Engineering \& Tea Technology, School of Applied Sciences and Technology, Shahjalal University of Science \& \\ Technology, Sylhet, Bangladesh
}

Email address:

zhennangu@jiangnan.edu.cn (Zhennan Gu)

To cite this article:

Md. Shofiul Azam, Zhennan Gu, Haiqin Chen, Yong Q. Chen. Using Mortierella alpina as a Novel Platform for Lipid Synthesis Inhibitor Screening. Advances in Bioscience and Bioengineering. Vol. 3, No. 1, 2015, pp. 1-10. doi: 10.11648/j.abb.20150301.11

\begin{abstract}
The screening method for discovering new lipid synthesis inhibitors has not been well developed. Lipid synthesis genes are responsible for the synthesis of fatty acids in normal and tumor cells. Mortierella alpina(M. alpina) fungus has been found to produce large amounts of fatty acids because it possesses a full complement of lipid synthesis genes. We therefore hypothesized that $M$. alpina could be a good screening tool to find new compounds that inhibit fatty acid synthesis. We developed a M. alpina liquid culture based method to analyze the inhibitory effects of lipid synthesis inhibitors. We applied a color indicator method to monitor the oil production using some well documented lipid inhibitors (C75, Cerulenin) to verify the system, and analyzing pictures using image analysis software. The experimental drug nocodazole inhibited the lipid production in M. alpina almost to the same extent as the control inhibitors. Compared with biomass and protein levels, there was a profound effect on fatty acid level. We report the development of a fast and effective method for screening lipid synthesis inhibitors which can be used against obesity and cancer. This method can further be used to screen additional lipid and fatty acid synthesis inhibitors from natural compound libraries.
\end{abstract}

Keyword: Fatty Acid Synthase, Image Analysis Software, Lipid Synthesis Inhibitor, Mortierella alpina, Nocodazole, Screening System

\section{Introduction}

M. alpina is an oleaginous fungus that can produce lipids amounting up to $50 \%$ of its dry weight[1]. These lipids are mostly composed of triacylglycerol, with high quantities of arachidonic acid (AA; 20:4n-6) [2,3]. M. alpina can synthesize saturated fatty acids (SAFAs) monounsaturated fatty acid (MUFAs), and polyunsaturated fatty acid (PUFAs) de novo, and due to its high lipid content, this organism provides an interesting model for studying lipid metabolism[4,5]. M. alpina ATCC32222 has a unique ability to synthesize a wide range of fatty acids and has several advantages not only as an industrial strain, but also as a model for lipogenesis studies [6]. M. alpina can produce ecosapentanoic acid (EPA) efficiently when grown at a temperature under $20^{\circ} \mathrm{C}$ through the omega-3( $\left.\omega 3\right)$ pathway and its lipogenesis is simple[7,8].

The high level of fat in the Western diet has been implicated in the development of many human malignancies, including colon, breast, and ovarian carcinoma. Numerous studies have shown over expression of fatty acid synthase(FASN) in various human epithelial cancers, including prostate, ovary, colon, lung, endometrium and stomach cancers[9]. FASN is the main synthetic enzyme that catalyzes the NADPH-dependent condensation of malonyl$\mathrm{CoA}$ and acetyl-CoA to produce the 16-carbon saturated free fatty acid palmitate[10].

De novo synthesis of fatty acids accounts for more than $93 \%$ of triacylglycerol fatty acids in tumor cells. Fatty-acid synthesis can be a significant source of fatty acids for growth of tumor cells, considering the rates of free fatty acid and plasma triacylglycerol transport from the host to the tumor cells[11]. 
The increased de novo fatty-acid synthesis in tumor cells is caused by multiple mechanisms, including increased expression of lipogenic enzymes. In cancer cells, transcriptional regulation of the FASN gene is one of the important mechanisms of FASN over expression[12]. Cerulenin selectively targets cell membranes ( $\beta$-ketoacyl(acyl-carrier-protein (ACP)) synthase I/II (FabF/B)), forming a covalent bond with the catalytic cysteine in the active site with its tail occupying the long hydrophobic cavity that normally contains the growing acyl chain of the natural substrate[13]. In addition, other studies have shown that the human and fungal FASN genes are similar [14].

Filamentous fungi are ideal model systems for investigating the conserved microtubule based transport processes of complex multicellular eukaryotes [15,16]. A wide variety of drugs are able to bind to tubulin and modify its assembly properties. Nocodazole, vincristine, and colchicine block the polymerization of tubulin into microtubules. Microtubule depolymerization by nocodazole inhibited cholesterol and haemagglutinin transport to a similar extent [17]. In this study, we hypothesize that antibiotic nocodazole is able to stop or lower the FASN gene activity in $M$. alpina fungi. Phenotypic screening is now possible with oleaginous model organisms such as M. alpina, making it an ideal platform to discover lipid synthesis inhibitors that can be used in diseases caused by an excess of fat $[18,19]$.

The purpose of this study was to use M. alpina as a model system to evaluate a new inhibitor of lipid synthesis using image analysis software and lay the foundation for further studies to better understand the lipid biosynthesis pathway.

\section{Methods}

\subsection{Chemicals (Nocodazole, C75 and Cerulenin) for Suppressing the Fatty Acid Producing Enzymes}

Nocodazole stock solution in dimethylsulfoxide (DMSO, $10 \mathrm{mg} / \mathrm{mL}$ ) was prepared and stored at $-20^{\circ} \mathrm{C}$. Control treatments with DMSO indicated that DMSO at the concentrations used to introduce nocodazole to the fungi culture (up to $0.5 \%$ final DMSO concentration) did not alter fungal growth. M. alpina grown either in a liquid broth or in 24wells plate both was exposed to nocodazole, C75 or cerulenin at various concentrations $(0,1,2,5$ and $10 \mu \mathrm{M})$ for $24 \mathrm{~h}$, or $48 \mathrm{~h}[20]$.

\subsection{Fungal Strain, Culture Condition}

M. alpina ATCC32222 was inoculated on Potato Dextrose Agar and incubated for $20-30$ days at $28^{\circ} \mathrm{C}$. This strain was activated from its frozen form by transferring once in Kendrick broth and incubating at $28^{\circ} \mathrm{C}$ for $72 \mathrm{~h}$. The rate of inoculation was approximately $1 \%(\mathrm{v} / \mathrm{v})$ [21]. Five $\mathrm{ml}$ broth $\left(20 \mathrm{~g} / \mathrm{L}\right.$ Glucose, $5 \mathrm{~g} / \mathrm{L}$ Bacto yeast extract, $1 \mathrm{~g} / \mathrm{L} \mathrm{KH}_{2} \mathrm{PO}_{4}$, $0.25 \mathrm{~g} / \mathrm{L} \mathrm{MgSO}_{4}, 10 \mathrm{~g} / \mathrm{L} \mathrm{KNO}_{3}, 10 \mathrm{~g} / \mathrm{L}$ ) was added to three plates $(100 \mathrm{~mm})$. Spores were gently scraped of the surface with a sterile loop, filtrated through a 40 micron cell strainer, concentrated by centrifuging at $12,000 \times \mathrm{g}$ for $15 \mathrm{~min}$, suspended in a small volume of broth, enumerated using a hemocytometer, and kept at $-80^{\circ} \mathrm{C}$ in $30 \%$ glycerol at a density of approximately $10^{7}$ spores $/ \mathrm{ml}$. Alternatively, three $\mathrm{ml}$ of unconcentrated spore suspension was directly added into $45 \mathrm{ml}$ broth without $\mathrm{KNO}_{3}$ in a $250 \mathrm{~mL}$ flask covered with 8 layers of cheese cloth, and shaken at $200 \mathrm{rpm}, 28^{\circ} \mathrm{C}$ for 5 days. Cultures were blended using a blender(Model no: WF1112219,Waring Commercial, USA) for $5 \mathrm{sec} /$ pulse, 8 pulses, and then $0.3 \mathrm{~g}$ of wet mycelia was inoculated into $50 \mathrm{ml}$ broth without $\mathrm{KNO}_{3}$ in a $250 \mathrm{~mL}$ flask and shaken at $200 \mathrm{rpm}, 28^{\circ} \mathrm{C}$ for $48 \mathrm{~h}$. The above step was repeated once and the fungal culture in the proliferative phase was ready for experimental use. Mycelia were collected by vacuum filtration (Whatman grade No. 3 filter paper, $6 \mu \mathrm{m}$ ) and weighed. Samples were snap-frozen in liquid nitrogen pulverized and kept at $-80^{\circ} \mathrm{C}$ until analysis.

\subsection{TTC Staining and Quantification of Staining Degree}

Triphenyltetrazolium chloride (TTC) powder was dissolved in sterile distilled water at a concentration of $5 \mathrm{mg} / \mathrm{mL}$ at room temperature, then filtered through $0.22 \mu \mathrm{m}$ filter paper and stored at $-20^{\circ} \mathrm{C}$ until used[22]. The staining procedure was performed as described previously [23] with slight modifications. Blended fresh mycelia were cultured in micro plate liquid medium broth. $6.5 \%$ of TTC solution was added with fresh mycelia in each well and incubated in the dark for 2 days at $28^{\circ} \mathrm{C}$. Then the red Triphenylformazan(TF) formed in mycelia was extracted three times with $1 \% \mathrm{NaCl}$ at room temperature. The staining degree was quantified by measuring absorbance of TF in the ethyl acetate solvent at $485 \mathrm{~nm}$ by using a micro plate reader (Multiskan Gu, Thermo Scientific).

\subsection{Determination of Dry Cell Weight}

The fungal cells from the fermentation broth were harvested by filtration and washed twice with distilled water. Dry cells weights of biomass were determined by lyophilizing to obtain a consistent weight.

\subsection{Pixel Density Calculation by Image Analysis Software}

Image analysis was done according to a previously described technique [24] with slight modifications. The camera was placed $20 \mathrm{~cm}$ above the microplate, on a static support to ensure reproducible framing and shooting under identical conditions. Image analysis quantification of microplate image was carried out using Adobe Photoshop CS6. The analysis of micro plate images by Photoshop was performed by adjusting the image at threshold value of 130 . The image was converted to black and white. Each well was selected by a magic wand tool and the area was determined in terms of pixel numbers. Pixel densities in the selected area were measured by a histogram command in Photoshop software. 


\subsection{Fatty Acid Methyl Ester Analysis (Fame Method)}

Fatty acid methyl ester analysis was determined as described previously with slight modification [25]. Approximately $20 \mathrm{mg}$ of mycelia were used for each lipid extraction. Accurately weighed portions of pulverized mycelium were extracted using the method of Bligh and Dyer[26] under acidified conditions with pentadecanoic acid and heneicosanoic acid added as internal standards. The solvent from the fungal extract was removed under a stream of nitrogen. Lipids were saponified in $1 \mathrm{ml}$ of freshly prepared $5 \%$ ethanolic potassium hydroxide at $60^{\circ} \mathrm{C}$ for $1 \mathrm{~h}$ under an argon atmosphere[27]. After cooling, $1 \mathrm{ml}$ of water was added to the samples and nonsaponifiable lipids were extracted into $3 \mathrm{ml}$ of hexane. The aqueous layer was acidified with $220 \mathrm{ml}$ of $6 \mathrm{M}$ hydrochloric acid and the fatty acids extracted into $3 \mathrm{ml}$ of hexane. After removing the hexane in a stream of nitrogen, fatty acids were converted to methyl esters by first treating with $1 \mathrm{ml}$ of $0.5 \mathrm{M}$ methanolic sodium hydroxide at $100^{\circ} \mathrm{C}$ for $5 \mathrm{~min}$ under argon followed by $1 \mathrm{ml}$ of $14 \%$ methanolic boron trifluoride at $100^{\circ} \mathrm{C}$ for 5 min under argon gas. After cooling the sample was mixed with $2 \mathrm{ml}$ of hexane followed by $4 \mathrm{ml}$ of saturated aqueous sodium chloride. After separating the phases, aliquots of the hexane layers were diluted 24 fold with hexane and then analyzed by GC/MS. One $\mu \mathrm{l}$ was injected in the split less mode onto a $30 \mathrm{~m} \times 250 \mathrm{~mm}$ DBWAXETR column (Agilent Technologies, Santa Clara, California) with $0.25 \mu \mathrm{m}$ film thickness. The temperature program was as follows: $40^{\circ} \mathrm{C}$ for $5 \mathrm{~min}$, ramp to $120^{\circ} \mathrm{C}$ at $20^{\circ} \mathrm{C}$ per min, hold for one min, ramp to $140^{\circ} \mathrm{C}$ at $5^{\circ} \mathrm{C}$ per min, hold $5 \mathrm{~min}$, ramp to $220^{\circ} \mathrm{C}$ at $5^{\circ} \mathrm{C}$ per min, and hold for $17 \mathrm{~min}$. Helium was the carrier gas at a constant flow of $0.94 \mathrm{ml} / \mathrm{min}$. The mass spectrometer was operated in positive-ion electron impact mode with interface temperature $250^{\circ} \mathrm{C}$, source temperature $220^{\circ} \mathrm{C}$, and filament emission $250 \mu \mathrm{A}$. Spectra were acquired from $\mathrm{m} / \mathrm{z} 50$ to 550 with a scan time of $0.433 \mathrm{~s}$. Lower boiling fatty acid methyl esters were quantified using the pentadecanoic acid internal standard, whereas higher-boiling methyl esters were quantified using the heneicosanoic acid internal standard.

\subsection{Gene Prediction and Gene Searching}

Predicted genes in the M. alpina (ATCC32222) genome
(GenBank accession no. ADAG00000000) were identified by BLAST searches [28]. The synthesized primers were purchased from Shanghai Sunny Biotech Co. Ltd, Shanghai, China.

\subsection{Total RNA Extraction Procedure and cDNA Conversion Procedure}

Filtered $M$. alpina was kept at $-80^{\circ} \mathrm{C}$ until ready for assaying. Thereafter, $500 \mathrm{mg}$ of mycelia was ground into a fine powder in liquid nitrogen with a precooled mortar and pestle. Total RNA extraction was performed using Trizol Reagent (Invitrogen) according to the manufacturer's guidelines. RNA was subjected to RNase-free DNase digestion and then purified using the RNeasy Mini kit (Qiagen). The quantity and quality of total RNA were evaluated using a NanoDrop-2000 spectrophotometer (Thermo Scientific Technologies). Total RNA was reversetranscribed with the Prime Script RT reagent kit (Rever Tra Ace $^{\circledR}$ qPCR RT Kit, Toyobo, Osaka, Japan) following the manufacturer's instructions.

\subsection{Total Protein Extraction \& Inhibition Method}

Total protein extraction from $M$. alpina was performed using the $\mathrm{Mg} / \mathrm{CHAPS}$ protein extraction method[29]. Total fungal protein inhibition was determined by the Coomassie Blue (Bradford) protein assay method [30,31] with bovine serum albumin as a standard.

\subsection{Real-Time Quantitative RT-PCR (qPCR)}

qPCR was conducted with $2 \mu 1$ reverse-transcribed cDNA using a CFX Connect ${ }^{\mathrm{TM}}$ Real Time PCR System (Bio-Rad CFX) and Power SYBR Green PCR Master Mix (Bio-Rad) according to the manufacturer's guidelines. The primer pairs used for $\mathrm{qPCR}$ are shown in table1. The PCR cycling conditions were: $10 \mathrm{~s}$ at $95^{\circ} \mathrm{C}$, followed by $30 \mathrm{~s}$ at $60^{\circ} \mathrm{C}$ for a total of 40 cycles. The $18 \mathrm{~S}$ rDNA gene was used as internal the reference gene. Fold changes in gene expression were calculated using the formula $2^{-\Delta \Delta \mathrm{Ct}}$, where $\Delta \Delta \mathrm{Ct}$ is $\Delta \mathrm{Ct}$ (treatment)- $\Delta \mathrm{Ct}$ (control), $\Delta \mathrm{Ct}$ is $\mathrm{Ct}$ (target gene)- $\mathrm{Ct}$ (18S), and $\mathrm{Ct}$ is the cycle value at which the fluorescence of the gene of interest crosses the threshold level (User's Manual for CFX Connect ${ }^{\mathrm{TM}}$ Real-Time PCR system).

Table 1. Primer used in this study.

\begin{tabular}{|c|c|c|c|}
\hline S.N. & Gene Id/Enzyme names & Short name & Primer sequences used for qPCR(5'-3') \\
\hline \multirow[b]{2}{*}{1} & MA-00184-380 & \multirow[b]{2}{*}{$\mathrm{ACC}$} & \\
\hline & E.C.6.4.1.2 & & CAGAGACGTATCCGACCAGC \\
\hline \multirow{2}{*}{2} & MA-00073-327 & \multirow{2}{*}{ ELOVL } & AGAAGGCTCTCTCGACCCAT \\
\hline & E.C.2.3.1- Fatty acid elongase & & GCACGGTAGTTGTAGCCCAT \\
\hline \multirow{2}{*}{3} & MA-00268-54 & \multirow{2}{*}{ FADS15 } & CAAGCACAACACTCACCACG \\
\hline & E.C.1.14.19.3Delta-15 fatty acid desaturase & & TTCAGGACCATGAAACGCGA \\
\hline \multirow{2}{*}{4} & MA-00055-340 & \multirow{2}{*}{ FASN } & GATCCGAGGGTGACGCTAAG \\
\hline & E.C.2.3.1.86 Fatty acid synthase & & CATCATCGCGTTCTGCTTGG \\
\hline \multirow{2}{*}{5} & MA-00055-83 & \multirow{2}{*}{ ME } & TCGTCGACGCTGTTATCGAG \\
\hline & E.C.1.1.1.40 Malic Enzyme & & TGGGTTGGTACTTGTCGAGC \\
\hline \multirow{2}{*}{6} & MA-00182-344 & \multirow{2}{*}{ ACLY } & GTGCGTATTTTCGTCCGTCG \\
\hline & E.C.2.13.3.8 ATP-Citrate lyase & & GTGTTGTTGCCCAAGAGCTG \\
\hline
\end{tabular}




\begin{tabular}{|c|c|c|c|}
\hline S.N. & Gene Id/Enzyme names & Short name & Primer sequences used for $\mathrm{qPCR}\left(5^{\prime}-3^{\prime}\right)$ \\
\hline 7 & $\begin{array}{l}\text { MA-00090-189 } \\
\text { E. } 11.149 \text { Glucose-6-phosphate1-dehydrogenase }\end{array}$ & G6PD & $\begin{array}{l}\text { AGACCCAAGACGACAAGCAG } \\
\text { TCGACGATCAGCCGAATGAG }\end{array}$ \\
\hline 8 & $\begin{array}{l}\text { MA-00101-420 } \\
\text { E.C.2.7.1.1 Hexokinase }\end{array}$ & HK & $\begin{array}{l}\text { TACGACGCATTGGTGGAACA } \\
\text { CTGGACCCTTCTTCAGAGCG }\end{array}$ \\
\hline 9 & $\begin{array}{l}\text { MA-00173-202 } \\
\text { E.C.3.1.1.31 } \\
\text { 6-phosphogluconolactonase }\end{array}$ & PGLS & $\begin{array}{l}\text { CTGGATACACCCGGCCATTT } \\
\text { TTGTGCGTGGTTGAGGTGAT }\end{array}$ \\
\hline 10 & $\begin{array}{l}\text { MA-00334-131 } \\
\text { E.C.4.2.1.3 Aconitase }\end{array}$ & $\mathrm{ACO}$ & $\begin{array}{l}\text { CCAAGGATTCGCTCACTGGT } \\
\text { TTGAAGGGCTCCAAGAGCTG }\end{array}$ \\
\hline 11 & $\begin{array}{l}\text { MA-00067-296 } \\
\text { E.C.1.1.1.41 Isocitrate dehydrogenase }\end{array}$ & IDH & $\begin{array}{l}\text { CGCCATGAAGGAGTGGACTT } \\
\text { TGTTGAGGAACAGACCGTCG }\end{array}$ \\
\hline 12 & $\begin{array}{l}\text { MA-00173-204 } \\
\text { E.C.1.2.1.3 Aldehyde dehydrogenase }\end{array}$ & ALDH & $\begin{array}{l}\text { TGCAAGCGGTGGTTCCTATT } \\
\text { TTGCTCGTCCACTCATGGTC }\end{array}$ \\
\hline 13 & $\begin{array}{l}\text { MA-00073-100 } \\
\text { E.C.1.1.1.2 Alcohol dehydrogenase }\end{array}$ & $\mathrm{ADH}$ & $\begin{array}{l}\text { GTCAGGGTGAACGGCAACTA } \\
\text { CACCGATACCCATCACTCCG }\end{array}$ \\
\hline 14 & $\begin{array}{l}\text { MA-00055-13 } \\
\text { E.C.1.1.1.34 3-hydroxy-3-methylglutaryl-CoA }\end{array}$ & HMGCR & $\begin{array}{l}\text { TGACTGGGCTCTTGTTCGAC } \\
\text { GTAATGCATGGGCAGAAGCG }\end{array}$ \\
\hline 15 & 18S rDNA & & $\begin{array}{l}\text { CTATTGGCGGAGGTCTATTCGT } \\
\text { GCACGCATTCGGATAATTGGT }\end{array}$ \\
\hline
\end{tabular}

\subsection{Statistical Analysis}

All treatments and analysis were conducted in triplicate and the results were expressed as mean $\pm \mathrm{SD}$. The data was evaluated by statistical analysis of variance (ANOVA) and Duncan's multiple range test (MRT) using SPSS software version 20.0 to compare the effects of various factors. The standard deviation of the replicate values is shown as error bars in the values depicted on $\mathrm{Y}$ axis, $\mathrm{P}<0.05$ was considered statistically significant.

\section{Results}

\subsection{Comparison of the Degree of TTC Staining}

TTC staining was done to investigate the relationship between staining degree and lipid content in mycelia and AA in lipids. Results for the comparison of TTC staining degree are presented in Fig. 1. Results showed that the relative absorbance at $485 \mathrm{~nm}$ of M. alpina cultures decreased when $\mathrm{C} 75$, nocodazole, or cerulenin was added. It was further shown that the absorbance of mycelia stained also decreased in the presence of inhibitors. In general, nocodazole treatment registered a higher absorbance than C75 and cerulenin treatment. Furthermore, it was observed that the TTC staining degree of mycelia increased when AA content in lipids increased and able to produce red color when culture media/solution has reducing agent like archidionic acid [23]. From the figure1 it's clear that when only $M$. alpina absorbance was higher than when add the suppressor chemicals in the culture media. Also, when only M. alpina and TTC, that time higher absorbance compared to when we add also the suppressor chemicals, that time absorbance is less. Because, when we add the suppressor chemical, primarily it detain the lipid producing process.

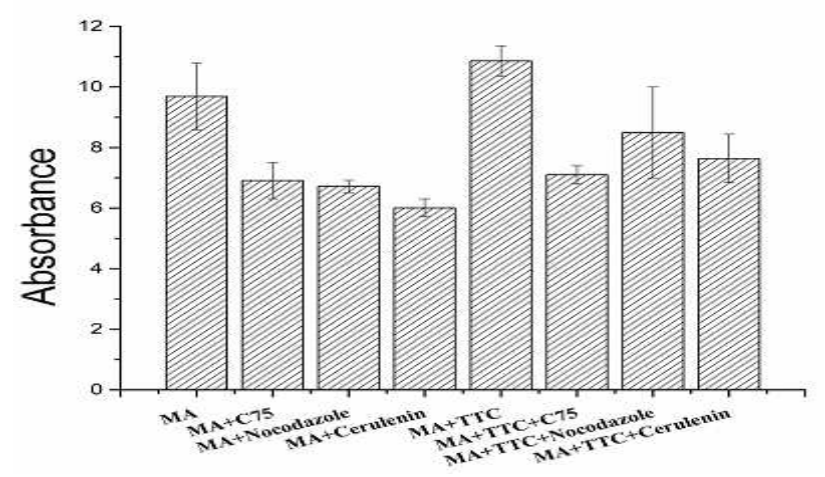

Fig. 1. TTC staining degree and phenotype screening comparison.

\subsection{Visual Screening \& Pixel Density Comparison}

The visual screening test was done primarily to determine, whether experimental drug nocodazole can reduce the fatty acid production in comparison with well-documented inhibitors. To check the whether suppressor chemicals inhibit the lipid production or not. To make relation between images of the 24 well and use image to make it quantification data for relative comparison with well documented inhibitor. Image analysis by Photoshop CS6 was performed to investigate a wide array of quantitative data from images and check the relative inhibition levels compared with control. The images used to compare the pixel density for the control and inhibitor treated samples are presented in Fig. 2 (D). The inhibitory effect of chemicals on fungal fatty level are observed, but not on the fungal normal growth. From physical observation with the naked eye Fig.2(A,B \&C) and using pixel density comparison with known inhibitors, we came to the conclusion that nocodazole can inhibit lipid synthesis. 

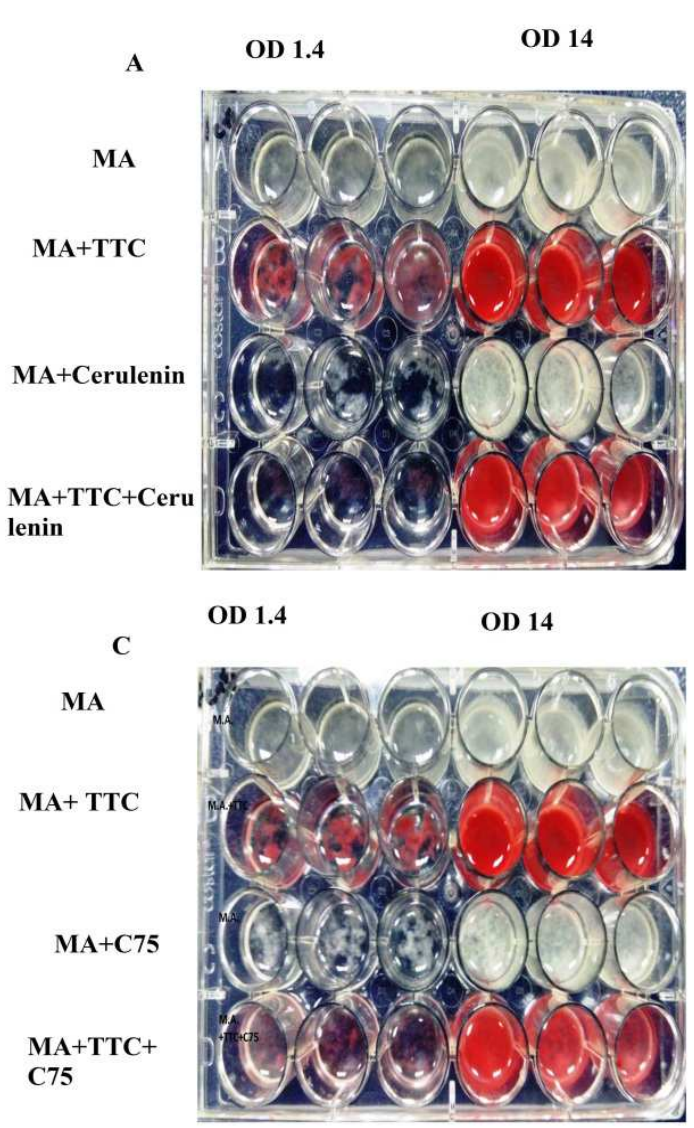

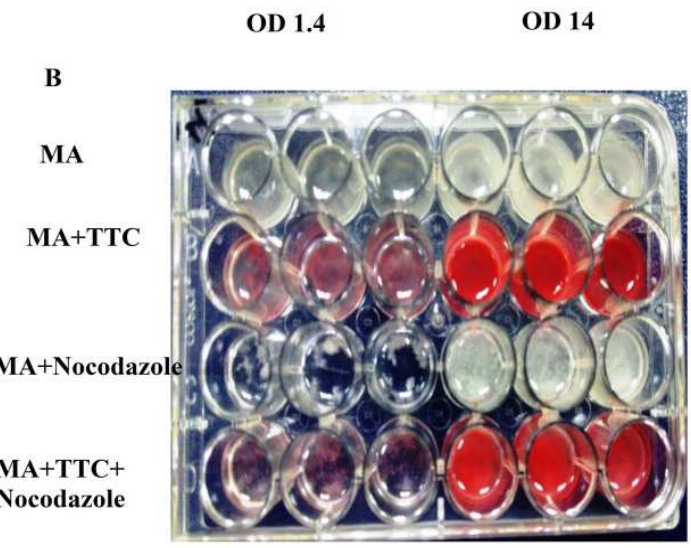

D

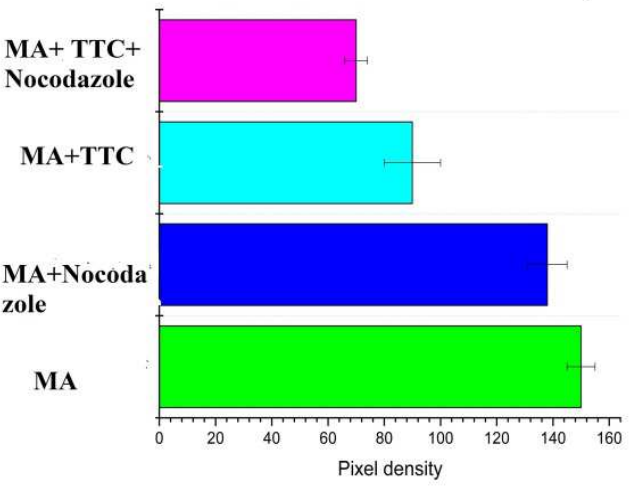

Fig. 2. $5 \mu M$ of each inhibitor without TTC and with TTC. Pixel density comparisons of relative data from image analysis software. (Fig.A. Cerulenin treatment, Fig.B. Nocodazole treatment, Fig.C. C75 treatment, Fig. D. Pixel density comparison.

\subsection{Biomass Comparison}

In order to check effect of inhibitory chemicals on the fungal growth, the $M$. alpina culture was treated with different chemicals under different fermentation conditions.
As shown in Table2, using two temperatures $\left(12^{\circ} \mathrm{C}\right.$ and $\left.28^{\circ} \mathrm{C}\right)$ in the presence and absence of $\mathrm{KNO}_{3}$, it was observed that as the chemicals increased, the total dry biomass decreased.

Table 2. Effect of C75, Nocodazole and Cerulenin on Dry Biomass of M. alpina after 5 days culture in liquid media at $12^{\circ} \mathrm{C}$ and $28^{\circ} \mathrm{C}$.

\begin{tabular}{|c|c|c|c|c|c|}
\hline Concentration $(\mu \mathrm{M})$ & Treatment & Conditions & & & \\
\hline & & $\begin{array}{l}12^{\circ} \mathrm{C} \\
(+) \mathrm{N}(\mathrm{g} / \mathrm{L})\end{array}$ & $(-) \mathrm{N}(\mathrm{g} / \mathrm{L})$ & $\begin{array}{l}28^{\circ} \mathrm{C} \\
(+) \mathrm{N}(\mathrm{g} / \mathrm{L})\end{array}$ & $(-) \mathrm{N}(\mathrm{g} / \mathrm{L})$ \\
\hline 0 & Control & $11.8 \pm 1.0$ & $9.6 \pm 0.06$ & $9.4 \pm 0.03$ & $10.4 \pm 0.22$ \\
\hline \multirow[t]{2}{*}{0} & DMSO & $11.8 \pm 1.8$ & $9.6 \pm 1.5$ & $9.4 \pm 1.3$ & $10.4 \pm 0.5$ \\
\hline & $\mathrm{C} 75$ & $11.2 \pm 1.3$ & $9.6 \pm 0.03$ & $6.8 \pm 0.1$ & $10.2 \pm 0.06$ \\
\hline \multirow[t]{3}{*}{1} & Nocodazole & $11.6 \pm 0.03$ & $10.4 \pm 0.09$ & $5.4 \pm 0.01$ & $10 \pm 0.04$ \\
\hline & Cerulenin & $11.8 \pm 0.07$ & $10 \pm 0.01$ & $7 \pm 0.03$ & $9.4 \pm 0.04$ \\
\hline & $\mathrm{C} 75$ & $9.6 \pm 0.04$ & $9 \pm 0.01$ & $4 \pm 0.05$ & $9.2 \pm 0.03$ \\
\hline \multirow[t]{3}{*}{2} & Nocodazole & $9.8 \pm 0.01$ & $9.8 \pm 0.08$ & $4 \pm 0.11$ & $9.4 \pm 0.07$ \\
\hline & Cerulenin & $9.6 \pm 0.1$ & $8.2 \pm 0.04$ & $5.8 \pm 0.2$ & $9 \pm 0.04$ \\
\hline & $\mathrm{C} 75$ & $8.2 \pm 0.05$ & $7.8 \pm 0.01$ & $3.3 \pm 0.09$ & $9 \pm 0.05$ \\
\hline \multirow[t]{3}{*}{5} & Nocodazole & $8.2 \pm 0.03$ & $7.6 \pm 0.02$ & $3.6 \pm 0.04$ & $9 \pm 0.17$ \\
\hline & Cerulenin & $8 \pm 0.11$ & $6.8 \pm 0.01$ & $4 \pm 0.01$ & $7.4 \pm 0.3$ \\
\hline & $\mathrm{C} 75$ & $7.8 \pm 0.07$ & $7.8 \pm 0.05$ & $2.4 \pm 0.03$ & $6 \pm 0.1$ \\
\hline \multirow[t]{2}{*}{10} & Nocodazole & $7.6 \pm 0.03$ & $7.4 \pm 0.01$ & $3.2 \pm 0.1$ & $5 \pm 0.01$ \\
\hline & Cerulenin & $6.6 \pm 0.05$ & $6.6 \pm 0.08$ & $3 \pm 0.3$ & $4.6 \pm 0.06$ \\
\hline
\end{tabular}


Dry biomass of $M$. alpina culture in day 5 mycelia gm per $\mathrm{L}$ liquid media. Averages \pm standard deviations are shown. $+\mathrm{N}_{2}$ represents presence of $\mathrm{KNO}_{3},-\mathrm{N}_{2}$ represents absence of $\mathrm{KNO}_{3}$

\subsection{Effect of Suppressor Chemicals on Fatty Acid Levels}

To investigate the lipid production rate, a comparison was made between our experimental drug nocodazole with two well documented inhibitors. Results presented in Table3 showed that the suppressor chemicals decreased significantly the fatty acid levels. The decrease was observed for both saturated and unsaturated fatty acid levels and this effect was observed highest at a $5 \mu \mathrm{M}$.

Table 3. Fatty acid concentration based on different concentration of inhibitors at $28^{\circ} \mathrm{C}$.

\begin{tabular}{|c|c|c|c|c|c|c|c|c|c|}
\hline Treatment & Concentration $(\mu \mathrm{M})$ & C14:0 & C16:0 & C16:1 & C16:1 & C18:0 & C18:1 & C18:2 & C18:2 \\
\hline Control & 0 & 30.14 & 337.9 & 3.37 & 4.87 & 222.0 & 274.09 & 3.36 & 106.63 \\
\hline DMSO & 0 & 28.36 & 298.59 & 3.58 & 4.62 & 214.81 & 285.75 & 4.87 & 119.34 \\
\hline $\mathrm{C} 75$ & 1 & 12.27 & 136.99 & 3.21 & 3.92 & 60.45 & 199.15 & 2.71 & 39.70 \\
\hline Cerulenin & 1 & 5.92 & 62.10 & 3.74 & 3.46 & 28.0 & 83.95 & 2.32 & 22.89 \\
\hline $\mathrm{C} 75$ & 2 & 4.68 & 44.26 & 0.60 & 2.21 & 39.6 & 21.52 & 0 & 18.2 \\
\hline Nocodazole & 2 & 4.7 & 7.99 & 2.5 & 1.1 & 67.8 & 27.3 & 1.4 & 21.78 \\
\hline $\mathrm{C} 75$ & 5 & 2.37 & 20.59 & 0.2 & 1.5 & 25.8 & 15.2 & 0 & 9.2 \\
\hline Nocodazole & 5 & 2.34 & 20.67 & 1.78 & 1.01 & 19.34 & 14.7 & 0 & 13.0 \\
\hline Cerulenin & 5 & 2.44 & 26.8 & 1.98 & 1.6 & 28.66 & 19.1 & 0 & 8.9 \\
\hline
\end{tabular}

Table 3. Continue.

\begin{tabular}{|c|c|c|c|c|c|c|c|c|c|}
\hline Treatment & Concentration $(\mu \mathrm{M})$ & C20:0 & C20:1 & C20:2 & C20:2 & C20:3 & C20:4 & C22:0 & C24:0 \\
\hline Control & 0 & 6.73 & 9.35 & 2.71 & 93.27 & 87.23 & 634.3 & 22.5 & 13.07 \\
\hline DMSO & 0 & 6.81 & 10.36 & 2.63 & 89.3 & 87.5 & 626.9 & 20.96 & 13.1 \\
\hline $\mathrm{C} 75$ & 1 & 3.39 & 2.97 & 2.23 & 40.26 & 34.89 & 118.48 & 4.44 & 3.4 \\
\hline Nocodazole & 1 & 5.75 & 5.42 & 2.25 & 34.24 & 59.40 & 262.6 & 7.81 & 3.21 \\
\hline Cerulenin & 1 & 2.11 & 1.55 & 1.95 & 36.2 & 17.6 & 64.97 & 2.09 & 3.1 \\
\hline $\mathrm{C} 75$ & 2 & 0.58 & 0.47 & 1.65 & 25.54 & 5.93 & 44.92 & 0 & 2.9 \\
\hline Nocodazole & 2 & 3.96 & 4.76 & 1.87 & 22.8 & 10.5 & 48.4 & 2.33 & 2.7 \\
\hline $\mathrm{C} 75$ & 5 & 0.55 & 4.26 & 1.22 & 19.5 & 5.1 & 35.1 & 0 & 0 \\
\hline Nocodazole & 5 & 1.19 & 1.23 & 1.3 & 6.19 & 8.2 & 36.6 & 1.3 & 0 \\
\hline Cerulenin & 5 & 0.6 & 3.78 & 0.9 & 10.6 & 6.9 & 32.7 & 1.4 & 0 \\
\hline
\end{tabular}

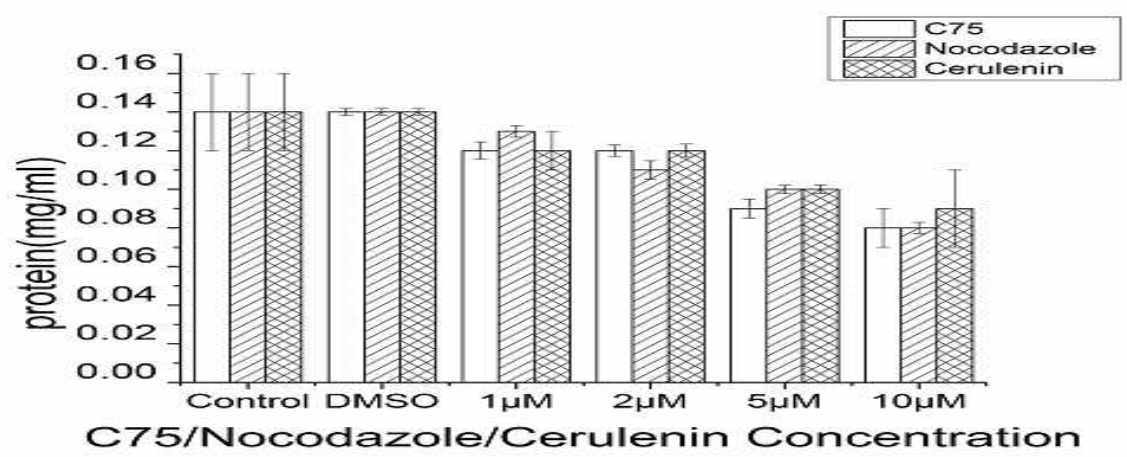

Fig. 3. Effect of inhibitors on total protein.

Values are means of three samples. Fatty acid shown in the table from per 1litre media and at $28^{\circ} \mathrm{C}$ and presence of nitrogen

\subsection{Comparison with Total Protein Inhibition}

Stability of the proteins after treatment with inhibitory chemicals was determined by measuring the protein concentration, shown in fig.3. The effect of inhibitory chemicals on protein levels were determined by measuring the protein concentration. The total protein level for the control and DMSO treated fungi was almost the same when the media was treated with $\mathrm{C} 75$, nocodazole and cerulenin. There was a dose-dependent inhibition of protein levels with each treatment.

\subsection{Gene Expression Analysis}

To investigate whether nocodazole inhibited the expression of lipid synthesis genes in M. alpina, qRT-PCR was performed to analyze the changes in the expression levels of genes involved in lipid biosynthesis during the course of the lipid accumulation. Total RNA samples were purified from mycelia collected from five day cultures. The 
relative expression levels of these genes were measured in triplicate by qPCR (Fig. 4). Following nocodazole treatment, the expression of FASN, ME, ACLY, and HMGGR was significantly decreased.
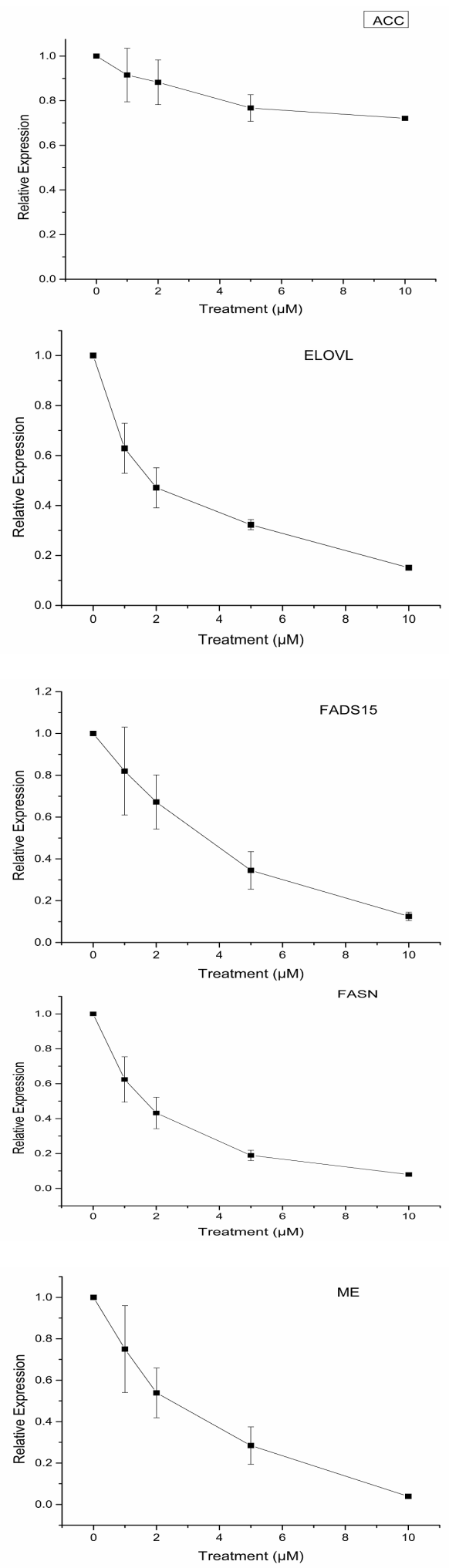
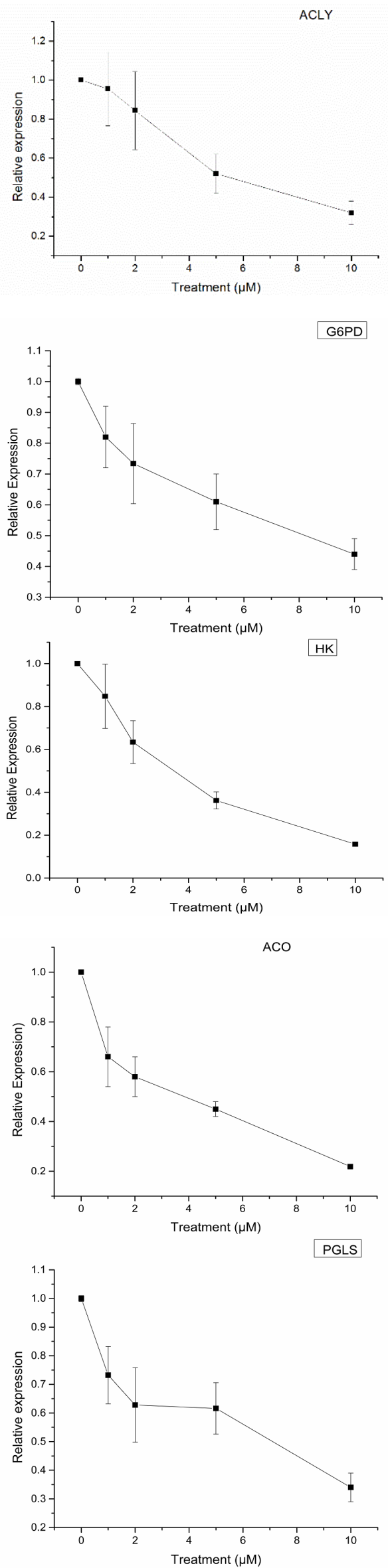

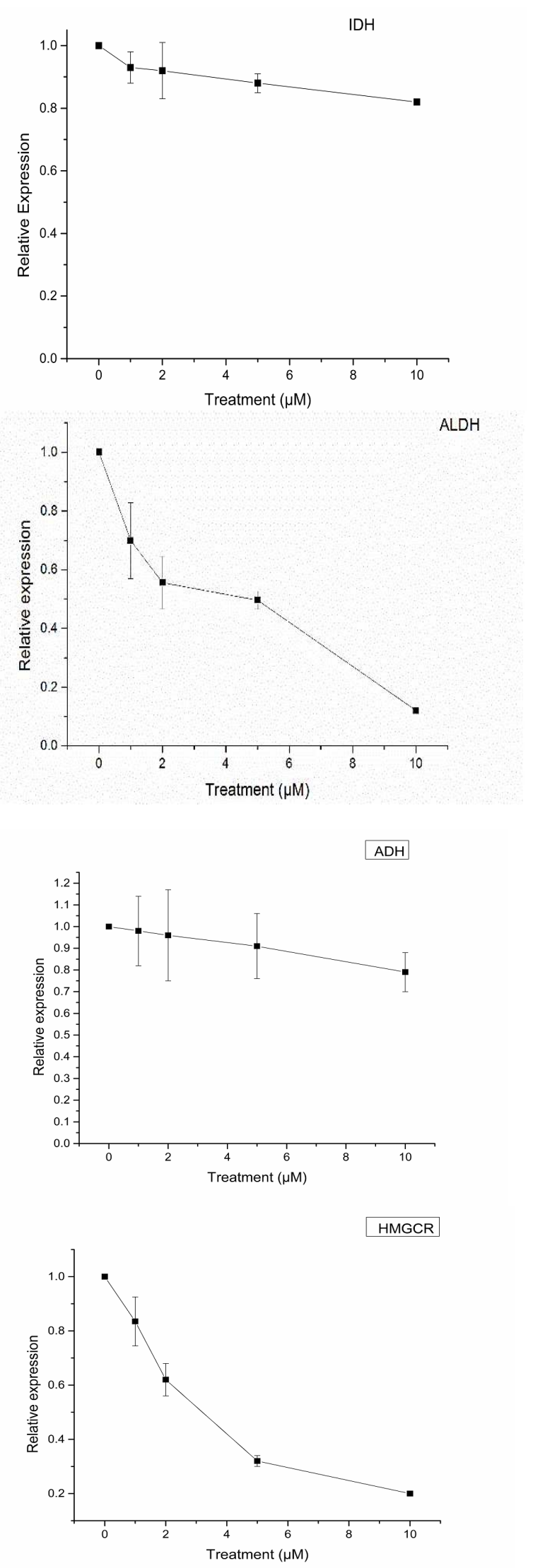

Fig. 4. Relative expression levels of (ACC, ELOVL, FADS15, FASN, ME, $A C L Y, G 6 P D, H K, P G L S, A C O, I D H, A L D H, A D H, H M G C R)$ genes during the accumulation of cell lipid.
But ACC, IDH and ADH genes were almost stable and nocodazole has little inhibition on them. The results clearly indicated that nocodazole could affect the regulation of de novo lipogenesis in $M$. alpina. The nocodazole induced decrease in the expression of lipogenic enzymes was accompanied by a decreased activity of the lipogenic pathway. The inhibition rate of gene expression level is highest at $5 \mu \mathrm{M}$ concentration.

\section{Discussion}

Reduction of TTC is mostly used as a biochemical test for the viability of living cells [32].It is generally thought that TTC is reduced by dehydrogenases [33,34]. TTC is absorbed by living cells, where it reacts with hydrogen atoms released by the dehydrogenase enzymes during cellular respiration. There are many dehydrogenases in fungi. However, only AAproducing fungus $M$. alpina could be stained red, Mucor rouxianus which does not produce $\mathrm{AA}$, could not be stained red. This indicated that there is a specific dehydrogenase only in M. alpina and not in Mucor rouxianus. On the basis of the results of our initial microplate screening, it can be concluded that nocodazole can be used as a lipid synthesis inhibitor.

We have observed three outcomes based on fungus growth and lipid phenotypes, depending on both the compound structure and concentration :( 1) increase in growth but decrease in lipid production; (2) decrease in both growth and lipid production; (3) no effect on growth or lipid production. The Biomass of M. alpina after 5 days culture in liquid media at different temperatures, with several fatty acid inhibitors concentration and in the presence and absence of nitrogen showed significant fluctuations. At high temperature, nitrogen deprivation has positive effect on growth. Cultures treated with fatty acid inhibitors also showed higher growth rates under nitrogen deficiency. Cerulenin had more profound effects on cell growth than the other two inhibitors.

The ability of nocodazole to rapidly enter cells and bind tubulin makes it a useful probe for studying microtubulebased processes[35]. Since nocodazole inhibits phospholipid synthesis as well, treated cells may decrease the amount of their intracellular lipids.

Nocodazole reduced the growth of all the fungi tested at concentrations of 2 and $5 \mu \mathrm{M}$, caused strong depolymerization. Nocodazole has been reported to be stable in biological media for more than 7 days. It was also difficult to record the immediate effects of the drug treatments on extension growth. During prolonged incubation times, the effect of the drug can be decreased due to breakdown. However, the activity of nocodazole has been reported to remain unchanged up to 7 days [36].

It is clear that fewer lipids are present after treatment with nocodazole. It is also visible that dry mass and protein levels also are decreased. Concerning mRNA levels it seems quite visible that all levels are decreased in some extent upon treatment. This general reduction might be due to the effect that nocodazole has on cell cycle. Nocodazole is able to arrest cells in G2, M phase. Then, the reduction on lipid 
concentrations might be the effect of a more general regulation, rather than a specific lipid synthesis inhibition.

We have demonstrated that an image-based screening of a broad biological problem can be used for both basic cell biology and therapeutic drug discovery. In the future it will be important to find additional natural compounds that specifically target lipids and total protein levels. Once the images were collected and stored, the next problem is to turn them into quantitative phenotypic information. Perhaps the single largest challenge in image-based screening is data analysis.

The total protein level was almost identical in all treatments. But at lower chemical concentrations inhibition was not as dramatic as compared to higher concentration $(5 \mu \mathrm{M})$. This knowledge could be helpful in designing new anti-tumor strategies based on manipulation of lipid requirements of tumor cells. It can also provide an alternative for the use of inhibitors of the lipolytic pathway while at the same time inhibiting the de novo fatty acid synthesis.

The main highlights of this research was: (1) M. alpina can be used as a host to screen lipid synthesis inhibitor; (2)Antibiotic drug nocodazole can be used as a lipid synthesis inhibitor; (3) Nocodazole can reduce the fatty acid and lipid synthesis genes expression level; (4) This system allow discovery of new lipid synthesis inhibitors from already known compounds

\section{Conclusion}

In this study, new lipid synthesis inhibitors were screened using M. alpina as a model organism platform in order to reduce the lipid producing gene expression and better understand the fatty acid biosynthesis mechanism. This study describes the development of a fast and effective platform which can be used to screen lipid synthesis inhibitors. Furthermore, this method can also be used to screen additional lipid and fatty acid synthesis inhibitors from natural compound libraries. It can be concluded that $M$. alpina can be an important tool in the drug discovery process using in vitro model system.

\section{Acknowledgements}

The study was supported by the Program for New Century Excellent Talents (NCET-13-0831), the National Natural Science of China (No. 212776108, 31125021, 31471128, and 31400038), the Program for Changjiang Scholars and Innovative Research Team in University (IRT1249), and the Fundamental Research Funds for the Central Universities( No. JUSRP51320B).

\section{References}

[1] S.Y. Ho, Y. Jiang, F. Chen, Polyunsaturated fatty acids (PUFAs) content of the fungus Mortierella alpina isolated from soil, J Agric Food Chem 55 (2007) 3960-3966.
[2] H.D. Jang, Y.Y. Lin, S.S. Yang, Effect of culture media and conditions on polyunsaturated fatty acids production by Mortierella alpina, Bioresour Technol 96 (2005) 1633-1644.

[3] C. Ratledge, Fatty acid biosynthesis in microorganisms being used for Single Cell Oil production, Biochimie 86 (2004) 807815.

[4] S. Shimizu, S. Jareonkitmongkol, Mortierella Species (Fungi): Production of C20 Polyunsaturated Fatty Acids, in: Y.P.S. Bajaj (Ed.), Medicinal and Aromatic Plants VIII, Springer Berlin Heidelberg, 1995, pp. 308-325.

[5] N. Amano, Y. Shinmen, K. Akimoto, H. Kawashima, T. Amachi, S. Shimizu, H. Yamada, Chemotaxonomic significance of fatty-acid composition in the genus Mortierella (Zygomycetes, Mortierellaceae), Mycotaxon 44 (1992) 257265.

[6] E. Sakuradani, S. Shimizu, Single cell oil production by Mortierella alpina, J Biotechnol 144 (2009) 31-36.

[7] E. Sakuradani, Advances in the Production of Various Polyunsaturated Fatty Acids through Oleaginous Fungus Mortierella alpina Breeding, Bioscience, Biotechnology, and Biochemistry 74 (2010) 908-917.

[8] E. Sakuradani, A. Ando, J. Ogawa, S. Shimizu, Improved production of various polyunsaturated fatty acids through filamentous fungus Mortierella alpina breeding, Appl Microbiol Biotechnol 84 (2009) 1-10.

[9] F.P. Kuhajda, Fatty-acid synthase and human cancer: new perspectives on its role in tumor biology, Nutrition 16 (2000) 202-208.

[10] L. Weiss, G.E. Hoffmann, R. Schreiber, H. Andres, E. Fuchs, E. Korber, H.J. Kolb, Fatty-acid biosynthesis in man, a pathway of minor importance. Purification, optimal assay conditions, and organ distribution of fatty-acid synthase, Biol Chem Hoppe Seyler 367 (1986) 905-912.

[11] M. Ookhtens, R. Kannan, I. Lyon, N. Baker, Liver and adipose tissue contributions to newly formed fatty acids in an ascites tumor, 1984.

[12] F.P. Kuhajda, Fatty acid synthase and cancer: new application of an old pathway, Cancer Res 66 (2006) 5977-5980.

[13] A.C. Price, K.H. Choi, R.J. Heath, Z. Li, S.W. White, C.O. Rock, Inhibition of beta-ketoacyl-acyl carrier protein synthases by thiolactomycin and cerulenin. Structure and mechanism, J Biol Chem 276 (2001) 6551-6559.

[14] M. Leibundgut, T. Maier, S. Jenni, N. Ban, The multienzyme architecture of eukaryotic fatty acid synthases, Curr Opin Struct Biol 18 (2008) 714-725.

[15] C. Goswami, L. Goswami, Filamentous microtubules in the neuronal spinous process and the role of microtubule regulatory drugs in neuropathic pain, Neurochem Int 57 (2010) 497-503.

[16] M.J. Egan, M.A. McClintock, S.L. Reck-Peterson, Microtubule-based transport in filamentous fungi, Curr Opin Microbiol 15 (2012) 637-645.

[17] S. Heino, S. Lusa, P. Somerharju, C. Ehnholm, V.M. Olkkonen, E. Ikonen, Dissecting the role of the golgi complex and lipid rafts in biosynthetic transport of cholesterol to the cell surface, Proc Natl Acad Sci U S A 97 (2000) 8375-8380. 
[18] A.K. Franz, M.A. Danielewicz, D.M. Wong, L.A. Anderson, J.R. Boothe, Phenotypic screening with oleaginous microalgae reveals modulators of lipid productivity, ACS Chem Biol 8 (2013) 1053-1062.

[19] J.C. Yarrow, G. Totsukawa, G.T. Charras, T.J. Mitchison, Screening for cell migration inhibitors via automated microscopy reveals a Rho-kinase inhibitor, Chem Biol 12 (2005) 385-395.

[20] S. Cooper, G. Iyer, M. Tarquini, P. Bissett, Nocodazole does not synchronize cells: implications for cell-cycle control and whole-culture synchronization, Cell Tissue Res 324 (2006) 237-242.

[21] R. Ashraf, N.P. Shah, Selective and differential enumerations of Lactobacillus delbrueckii subsp. bulgaricus, Streptococcus thermophilus, Lactobacillus acidophilus, Lactobacillus casei and Bifidobacterium spp. in yoghurt--a review, Int J Food Microbiol 149 (2011) 194-208.

[22] S.H. Moussa, A.A. Tayel, A.A. Al-Hassan, A. Farouk, Tetrazolium/Formazan Test as an Efficient Method to Determine Fungal Chitosan Antimicrobial Activity, Journal of Mycology 2013 (2013) 1-7.

[23] M. Zhu, L.J. Yu, Z. Liu, H.B. Xu, Isolating Mortierella alpina strains of high yield of arachidonic acid, Lett Appl Microbiol 39 (2004) 332-335.

[24] P. Phattanawasin, U. Sotanaphun, I. Kanchanaphibool, L. Sriphong, N. Piyapolrungroj, A Comparison of Image Analysis Software for Quantitative TLC, Silpakorn U Science \& Tech J 5 (2011).

[25] L. Wang, W. Chen, Y. Feng, Y. Ren, Z. Gu, H. Chen, H. Wang, M.J. Thomas, B. Zhang, I.M. Berquin, Y. Li, J. Wu, H. Zhang, Y. Song, X. Liu, J.S. Norris, S. Wang, P. Du, J. Shen, N. Wang, Y. Yang, W. Wang, L. Feng, C. Ratledge, H. Zhang, Y.Q. Chen, Genome characterization of the oleaginous fungus Mortierella alpina, PLoS One 6 (2011) e28319.

[26] E.G.a. Bligh, W.J. Dyer, A rapid method of total lipid extraction and purification, Can.J.Biochem.Physiol. 37 (1959) 911-917.
[27] L.D. Metcalfe, A.A. Schmitz, J.R. Pelka, Rapid Preparation of Fatty Acid Esters from Lipids for Gas Chromatographic Analysis, Analytical Chemistry 38 (1966) 514-515.

[28] S.W. White, J. Zheng, Y.M. Zhang, Rock, The structural biology of type II fatty acid biosynthesis, Annu Rev Biochem 74 (2005) 791-831.

[29] V. Bhadauria, Y.L. Peng, Optimization of a protein extraction technique for fungal proteomics, Indian J Microbiol 50 (2010) 127-131.

[30] M.M. Bradford, A rapid and sensitive method for the quantitation of microgram quantities of protein utilizing the principle of protein-dye binding, Anal Biochem 72 (1976) 248-254.

[31] C.M. Stoscheck, Quantitation of protein, 182 (1990) 50-68.

[32] J.P. Palta, J. Levitt, E.J. Stadelmann, Plant viability assay, Cryobiology 15 (1978) 249-255.

[33] D.A. Musser, A.R. Oseroff, The use of tetrazolium salts to determine sites of damage to the mitochondrial electron transport chain in intact cells following in vitro photodynamic therapy with Photofrin II, Photochem Photobiol 59 (1994) 621-626.

[34] P.R. Rich, L.A. Mischis, S. Purton, J.T. Wiskich, The sites of interaction of triphenyltetrazolium chloride with mitochondrial respiratory chains, FEMS Microbiology Letters 202 (2001) 181-187.

[35] R.J. Vasquez, B. Howell, A.M. Yvon, P. Wadsworth, L. Cassimeris, Nanomolar concentrations of nocodazole alter microtubule dynamic instability in vivo and in vitro, Mol Biol Cell 8 (1997) 973-985.

[36] S.S. Niini, M. Raudaskoski, Response of Ectomycorrhizal Fungi to Benomyl and Nocodazole - Growth-Inhibition and Microtubule Depolymerization, Mycorrhiza 3 (1993) 83-91. 